\title{
Abuse in the Elderly-Cost Driver in a Health Care System?
}

\author{
Mindaugas Stankunas, PhD, ${ }^{1,2}$ Mark Avery, MBus(Res), Jutta Lindert, PhD,,4 \\ Ramune Kalediene, PhD, Ian Edwards, MHA, ${ }^{2}$ Mirko Di Rosa, PhD, ${ }^{5}$ Francisco Torres-Gonzalez, PhD, \\ Elisabeth loannidi-Kapolou, PhD?, Henrique Barros, $\mathrm{PhD}^{8}$, Skirmante Sauliune, PhD, \\ and Joaquim J.F. Soares, $\mathrm{PhD}^{9}$
}

$\mathbf{T}$ HE ABUSE OF OLDER PERSONS within the community is a source of major concern in Europe and beyond. Although elder abuse has historically been considered primarily a social welfare issue and a problem of aging, a more contemporary viewpoint is that it is a population health issue. ${ }^{1}$ Findings from the cross-national abuse survey, ABUEL (Abuse of the Elderly in Europe), conducted in 2009 demonstrate that $26.0 \%$ of people aged 60-84 years living in 7 European urban communities (Stuttgart, Germany; Athens, Greece; Ancona, Italy; Kaunas, Lithuania; Porto, Portugal; Granada, Spain; Stockholm, Sweden) experienced some form of abuse during the 12 months prior to the survey. The survey provides an estimation of 433,256 people in this age group who experience any type of abuse every year. ${ }^{2}$ Regardless of the nature or type of abuse, it may lead to physical and mental health problems and decreased quality of life for older persons. This may lead to more intensive use of health care services and additional expenditures for health systems. However, this association is investigated only occasionally and needs more attention from researchers and decision makers.

Findings from the "Elder abuse: a multinational prevalence survey-ABUEL" project ${ }^{3}$ suggest the existence of significant differences in use of health care related to various types of abuse. A higher proportion of respondents who experienced abuse declared that they had a contact with a health care provider in the last 12 months compared with nonabused respondents $(95.0 \%$ vs. $91.2 \%, P<0.05)$. Similar trends have been estimated for specific types of abuse: psychological (95.4\% vs. $90.9 \%, P<0.05)$, physical (95.2\% vs. $91.9 \%, P>0.05)$, physical injuries $(100 \%$ vs. $91.9 \%$, $P<0.001)$, and sexual abuse $(100 \%$ vs. $92.0 \%, P<0.001)$. However, an inverse trend was observed with financial abuse/ maltreatment $(88.2 \%$ vs. $92.1 \%)$. Logistic regression (the
"Enter" model was used and included sex, age, education, marital status, and living and economic conditions) revealed that an experience of any type of abuse was statistically associated with risk for using health care services (odds ratio $=2.09,95 \%$ confidence interval $1.51-2.89$ ).

The presented findings suggest that abuse can be identified as a risk factor for more intensive use and costs of health care services. Although there is a lack of global research on costs of elder abuse to health care, studies from the United States indicate that the economic impact on health care costs is significant. ${ }^{4}$ There are many contributing factors to abuse and they must be addressed to mitigate and stop this abuse. We need to know more about elder abuse and related factors to fully understand this phenomenon. The majority of research data on the associations between elder abuse and health/health care are based on crosssectional studies. This does not provide information on causality. The lack of comprehensive information about the extent of elder abuse, its "risk" factors and effects, could be a serious obstacle for planning and implementing effective elder abuse prevention and treatment programs. The development of evidence-based public health policies in this area is critical for our communities and also for reducing the impact on health care services and costs.

\section{Author Disclosure Statement}

The authors declared no conflicts of interest with respect to the research, authorship, and/or publication of this letter.

The ABUEL (Abuse of Elderly in the Europe) was supported by the Executive Agency for Health and Consumers (EAHC) (Grant No., A/2007123) and conducted with the help of the ABUEL groups in each participating country.

\footnotetext{
${ }^{1}$ Department of Health Management, Lithuanian University of Health Sciences, Kaunas, Lithuania.

${ }^{2}$ Health Service Management Department, Centre for Health Innovation, School of Medicine, Griffith University, Gold Coast, Queensland, Australia.

${ }^{3}$ Department of Public Health, University of Emden, Emden, Germany.

${ }^{4}$ Brandeis University, Waltham, Massachusetts.

${ }^{5}$ Centre for Socio-Economic Research on Aging, Italian National Institute of Health and Science on Aging (INRCA), Ancona, Italy.

${ }^{6}$ Centro de Investigación Biomedica en Red de Salud Mental (CIBERSAM), University of Granada, Granada, Spain.

${ }^{7}$ Department of Sociology, National School of Public Health, Athens, Greece.

${ }^{8}$ Department of Hygiene and Epidemiology, Faculty of Medicine, University of Porto, Porto, Portugal.

${ }^{9}$ Department of Health Sciences, Section of Public Health Sciences, Mid Sweden University, Sundsvall, Sweden.
} 


\section{References}

1. World Health Organization. World report on violence and health. Geneva: World Health Organization; 2002.

2. Soares JJ, Barros H, Torres-Gonzales F, et al. Abuse and Health Among Elderly in Europe. Kaunas, Lithuania: Lithuanian University of Health Sciences Press; 2010.

3. Lindert J, Luna J, Torres-Gonzalez F, et al. Study design, sampling and assessment methods of the European study 'abuse of the elderly in the European region.' Eur J Public Health. 2012;22:662-666.
4. Knapp R. The impact of interpersonal violence on health care. Nurs Clin North Am. 2011;46:465-470.

Address correspondence to: Dr. Mindaugas Stankunas Department of Health Management Lithuanian University of Health Sciences A. Mickevičiaus g. 9, LT 44307, Kaunas, Lithuania

E-mail: mindstan@gmail.com 